\title{
Cathartic Corridors: Queering Linearity in Final Fantasy XIII
}

\section{Gaspard Pelurson}

School of Cultural Studies and Humanities, Leeds Beckett University, Leeds, United Kingdom

\section{g.g.pelurson@leedsbeckett.ac.uk}

Gaspard Pelurson is a Lecturer in Media at the School of Cultural Studies and Humanities at Leeds Beckett University. His research and social engagement has, to date, focused on gender, sexuality and queerness in video games and popular culture. He received his $\mathrm{PhD}$ in Media and Cultural Studies from the University of Sussex. His work explores queer manifestations and practices in video games, with an overall goal of highlighting the politics of gaming culture. 